\section{Autoantikörper gegen Laktoferrin}

\author{
W. Stöcker \\ Euroimmun Medizinische Labordiagnostika AG, Lübeck, \\ Deutschland
}

Synonym(e) Autoantikörper gegen DNA-gebundenes Laktoferrin

Englischer Begriff autoantibodies against lactoferrin

Funktion - Pathophysiologie Laktoferrin (Laktotransferrin) ist ein Eisen-bindendes Protein, das aus einer Peptidkette mit 2 an Asparagin gebundenen Oligosacchariden besteht und zur Transferrinfamilie gehört. Es wird in neutrophilen Granulozyten sowie in Drüsenepithelzellen gebildet. Laktoferrin findet sich in Serum, Gallensaft, Sperma, Pankreassekret, Urin, Stuhl, Bronchialsekret und vor allem in der Muttermilch (ca. 5,5 g/L). Jedes Laktoferrinmolekül kann 2 Eisen-III-Ionen binden und dadurch insbesondere in der Schleimhaut das Wachstum von Bakterien und Pilzen, die zum Wachstum Eisen benötigen, hemmen.

Untersuchungsmaterial Serum, Plasma.

Probenstabilität Autoantikörper sind bei $+4{ }^{\circ} \mathrm{C}$ bis $\mathrm{zu}$ 2 Wochen lang beständig, bei $-20{ }^{\circ} \mathrm{C}$ über Monate und Jahre hinweg.

Analytik Das Zielantigen der Autoantikörper gegen Laktoferrin ist das in den zytoplasmatischen Granula der neutrophilen Granulozyten lokalisierte Laktoferrin. Nachweis durch indirekte Immunfluoreszenz ( $>$ Immunfluoreszenz, indirekte). Spezielle durch hohe Salzkonzentrationen depletierte und selektiv mit Laktoferrin beaufschlagte Granulozytensubstrate reagieren spezifisch mit den Seren von Patienten mit Colitis ulcerosa und mit primär-sklerosierender Cholangitis.

Für die Bestimmung der Anti-Laktoferrin-Antikörper in der Diagnostik der Colitis ulcerosa und der primär-sklerosierenden Cholangitis kommt es darauf an, dass das Laktoferrin in DNA-gebundener Form vorliegt. Das wurde in der Vergangenheit nicht beachtet, sodass die Bedeutung dieser Antikörper in der Gastroenterologie widersprüchlich beurteilt und unterschätzt wurde.

\section{Referenzbereich - Erwachsene Negativ.}

Indikation Der serologische Nachweis der Autoantikörper gegen DNA-gebundenes Laktoferrin kann zur Diagnose chronisch entzündlicher Darm- und Lebererkrankungen beitragen. Mit Laktoferrin angereicherte Granulozyten reagierten bei Colitis ulcerosa in $72 \%$ (Morbus Crohn $3 \%$, primärsklerosierende Cholangitis $42 \%$, gesunde Blutspender $0 \%$ ).

\section{Literatur}

Komorowski L, Teegen B, Probst C, Schlumberger W, Stöcker W (2009) ELISA for the detection of autoantibodies against DNA-bound lactoferrin in ulcerative colitis. In: Conrad K et al (Hrsg) From pathogenesis to therapy of autoimmune diseases. Pabst Science Publishers, Lengerich, S 474-475

Teegen B, Niemann S, Probst C, Schlumberger W, Stöcker W, Komorowski L (2009) DNA-bound lactoferrin is the major target for antineutrophil perinuclear cytoplasmic antibodies in ulcerative colitis. Ann N Y Acad Sci 1173:161-165 